\title{
Prevalence and Associated Factors of Diabetic Kidney Disease in Senegalese Patients: A Cross-Sectional Study in Saint-Louis
}

\author{
Sidy Mohamed Seck ${ }^{1,2 *}$, Dominique Doupa1 ${ }^{1}$, Seraphin Ahou ${ }^{3}$, Serigne Gueye ${ }^{4}$, \\ Macia Engerran², Lamine Gueye ${ }^{2}$ \\ ${ }^{1}$ Internal Medicine-Nephrology Department, Faculty of Health Sciences, University Gaston Berger, Saint-Louis, Senegal \\ ${ }^{2}$ UMI 3189 Environnement, santé, sociétés (CNRS/UCAD/Université de Bamako/CNRST Burkina-Faso), Faculté de Médecine de \\ Pharmacie et d'Odontostomatologie, Dakar, Senegal \\ ${ }^{3}$ Nephrology Department, Faculty of Health Sciences, University of Parakou, Parakou, Benin \\ ${ }^{4}$ Nephrology and Hemodialysis Department, $\mathrm{CH}$ Cahors, Cahors, France \\ Email: *sidymseck@gmail.com
}

How to cite this paper: Seck, S.M., Doupa, D., Ahou, S., Gueye, S., Engerran, M. and Gueye. L. (2020) Prevalence and Associated Factors of Diabetic Kidney Disease in Senegalese Patients: A Cross-Sectional Study in Saint-Louis. Open Journal of Nephrology, 10, 23-33.

https://doi.org/10.4236/ojneph.2020.101004

Received: December 3, 2019

Accepted: February 16, 2020

Published: February 19, 2020

Copyright $\odot 2020$ by author(s) and Scientific Research Publishing Inc. This work is licensed under the Creative Commons Attribution International License (CC BY 4.0).

http://creativecommons.org/licenses/by/4.0/

\begin{abstract}
Introduction: Diabetes is a leading cause of chronic kidney disease in the world. During the next decade, its burden is expected to increase in Africa with potential complications such as chronic kidney disease. However, epidemiology and risk factors of diabetic kidney disease are poorly described at population level. This study aimed to determine prevalence of diabetic kidney disease (DKD) in adult diabetics living in Saint-Louis, northern Senegal. Methods: A cross-sectional study including diabetic patients followed-up aged $\geq 18$ years during a five-year period (2013-2018) in Saint-Louis. Clinical and biological parameters were collected during annual community-based mass screening. Diabetes was defined as fasting blood glucose $\geq 1.26 \mathrm{~g} / \mathrm{L}$ confirmed by a second lab dosage. DKD was defined as persistence of albuminuria $\geq 30$ $\mathrm{mg} / 24 \mathrm{~h}$ and/or estimated glomerular filtration rate (eGFR) $<60 \mathrm{~mL} / \mathrm{min} / 1.73 \mathrm{~m}^{2}$. Data were analyzed with Stata 12.0. Results: We included a total of 1310 diabetic patients among whom $3.7 \%(95 \% \mathrm{CI}=1.4 \%-9.8 \%)$ presented DKD. Their mean age was $46.2 \pm 11.8$ years and sex-ratio was 0.7 . Micro-albuminuria and macro-albuminuria were present respectively in $59.2 \%$ and $18.4 \%$ of patients with DKD and half of them had a normal eGFR. Before the survey $89.8 \%$ of patients with DKD were not aware of their renal disease and only four of them had seen a nephrologist. After multivariate analysis, age $(\mathrm{OR}=1.5 ; 95 \% \mathrm{CI}=1.1-3.4)$, duration of diabetes $(\mathrm{OR}=1.2 ; 95 \% \mathrm{CI}=$ 1.6 - 4.4) and hypertension ( $\mathrm{OR}=2.5 ; 95 \% \mathrm{CI}=1.4-4.6)$ were associated with the presence of DKD in diabetic patients while no significant association was not found with gender, blood glucose level, smoking and familial history.
\end{abstract}


Conclusion: DKD is a frequent complication in diabetic adult population living in Saint-Louis. Early detection and management should be promoted in order to prevent progression to end-stage renal disease.

\section{Keywords}

Diabetes, Kidney Disease, Epidemiology, Saint-Louis

\section{Introduction}

Diabetic kidney disease (DKD) is a major complication of type 2 diabetes, characterized by elevated urinary albumin excretion rate, hypertension and/or a declining renal function that can lead to end-stage renal disease (ESRD). Currently diabetes is the world leading cause of ESRD undergoing dialysis treatment [1].

The rapid growth of DKD is due to the progression of type 2 diabetes epidemic combined with an increase in the life span of diabetic patients due to a better management of acute fatal complications [2]. This trend of increase in the proportion of chronic kidney disease attributable to diabetes is observed in both developed and developing countries [3].

During the next decade, the burden of diabetes is expected to increase in Africa with potential micro-angiopathic complications such as DKD and cardiovascular disease (CVD) that are the main causes of death [4].

Literature review

However, the epidemiology of DKD is still unknown at population level. This study aimed to describe the prevalence of diabetic kidney disease in adult population of Saint-Louis region (northern Senegal).

\section{Patients and Methods}

We performed a cross-sectional survey including diabetic patients aged $\geq 18$ years and recruited during community-based screening organized during five consecutive years of celebrating the World Diabetes Day (2013-2018) in Saint-Louis, northern Senegal. Clinical and biological parameters were collected using a questionnaire. Interviews combined with clinical examination and point-of-care tests (fasting blood glucose with Accuchek ${ }^{\circledR}$ device, urine albumin using Multistick Pro $^{\oplus}$ ). All cases with elevated finger glycemia or albumin positive urine dipsticks were completed by laboratory analyses at university hospital. Other biochemical tests included serum creatinine and total cholesterol. Diabetes was defined as fasting blood glucose $\geq 1.26 \mathrm{~g} / \mathrm{L}$ controlled by the lab test. Diabetic kidney disease was defined as presence of persistent micro- or macro-albuminuria (urine albumin-to-creatinine ratio $\geq 300 \mathrm{mg} / \mathrm{g}$ ) and/or estimated glomerular filtration rate $(\mathrm{eGFR})<60 \mathrm{~mL} / \mathrm{min} / 1.73 \mathrm{~m}^{2}$ using the MDRD equation [5].

Statistical analysis was performed with Stata 12.0. Baseline clinical and biological characteristics of patients with and without DKD were compared using 
the unpaired Student's $t$ test for continuous variables, and $\chi^{2}$ test for proportions. Logistic regression analysis was used to identify factors associated with DKD. The models included variables that were a priori known to be potential determinant of nephropathy, or that were found to be significantly different at baseline when we compared the two groups. For all statistical tests, we considered a significance level of $p \leq 0.05$.

\section{Results}

Among a total of 1310 diabetic patients included, 3.7\% (95\% CI $=1.4 \%-9.8 \%)$ presented overt DKD. Diabetic kidney disease prevalence was higher in men (4.3\%) compared to women (3.4\%) and showed an increasing trend with age (Figure 1). Their mean age was $46.2 \pm 11.8$ years and sex-ratio was 0.7. Micro-albuminuria and macroalbuminuria were present respectively in $59.2 \%$ and $18.4 \%$ of patients with DKD. Two of them had nephrotic range proteinuria. About half of patients with DKD had a normal eGFR and 20\% had stage $4-5$ chronic kidney disease (Figure 2). The main characteristics of participants with and without DKD are presented in Table 1.

Before the survey was conducted, $89.9 \%$ of patients were not aware of their kidney problem and only four of them had consulted a nephrologist and were treated with renin-angiotensin-aldosterone system (RAAS) inhibitors.

Univariate analysis identified age, gender, diabetes duration, hypertension, abdominal obesity and presence of familial history as significantly associated with DKD (see Table 2). Neither smoking nor level of glycated hemoglobin $\left(\mathrm{HbA}_{1} \mathrm{c}\right)$ was associated with occurrence of DKD.

After multivariate logistic analysis, only age, diabetic duration and hypertension remained significantly associated with DKD (see Table 3 ). The strongest risk factor was hypertension that multiplied risk of DKD by 2.5. Of note, any significant association was not found between DKD and gender, physical activity, smoking and familial history.

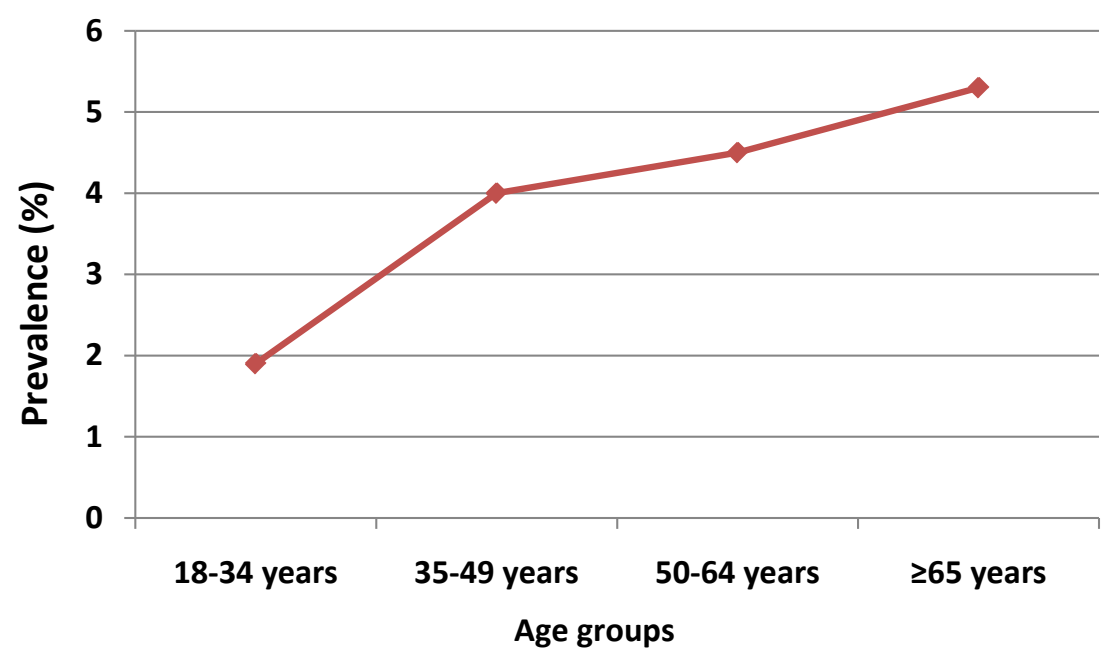

Figure 1. Prevalence of diabetic kidney disease across age groups. 


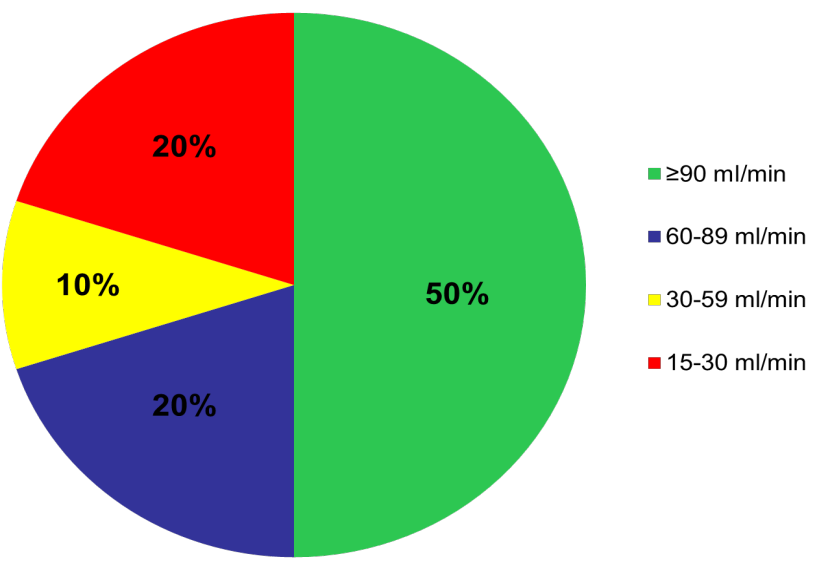

Figure 2. Glomerular filtration rate levels among patients with diabetic kidney disease.

Table 1. Baseline characteristics of diabetics with and without diabetic kidney disease.

\begin{tabular}{ccc}
\hline & $\begin{array}{c}\text { Normal kidney function } \\
(\mathrm{n}=1261)\end{array}$ & $\begin{array}{c}\text { Diabetic kidney disease } \\
(\mathrm{n}=49)\end{array}$ \\
\hline Age (years) & $37.8 \pm 14$ & $41.6 \pm 18$ \\
Gender (\% male) & 44.1 & 51.6 \\
Familial history of DKD & 10.3 & 44.9 \\
Duration of diabetes (years) & $9.7(3-25)$ & $15.8(5-23)$ \\
Smokers (\%) & 3.8 & 4.6 \\
Physical inactivity (\%) & 51.5 & 53.1 \\
Prevalence of retinopathy (\%) & 33.3 & 77.5 \\
Systolic BP (mm Hg) & $133.6 \pm 18.9$ & $133 \pm 17$ \\
Diastolic BP (mm Hg) & $80.6 \pm 9.4$ & $80 \pm 9$ \\
Glycated hemoglobin (\%) & $6.3 \pm 2.5$ & $9.1 \pm 2.8$ \\
Fasting glycemia (g/l) & $1.2(0.7-1.9)$ & $1.3(0.8-1.5)$ \\
Estimated GFR (ml/min/1.73m $\left.{ }^{2}\right)$ & $88.9 \pm 21.3$ & $64 \pm 18.9$
\end{tabular}

\section{Discussion}

\subsection{DKD Prevalence}

A global picture of DKD is not clearly shaped because high quality data from many countries are scare. In the United Kingdom Prospective Diabetes Study, the prevalence rate of nephropathy in types 2 diabetic patients was $30.8 \%$ [6].

In the sub-Saharan region reported data are more heterogeneous because of different definitions and methods used in studies. A systematic review showed that overall prevalence of kidney disease varied from $11 \%$ to $83.7 \%$ with albuminuria incidence of $94.9 \%$ after 10 years follow-up [7]. One study in Tanzanian patients found that $83.7 \%$ of diabetic patients attending a tertiary hospital presented an eGFR $\leq 60 \mathrm{ml} / \mathrm{min} / 1.73 \mathrm{~m}^{2}$ [8]. In this study, we found lower prevalence of kidney disease but this can be explained by the difference between our 
Table 2. Univariate analysis of factors associated with DKD.

\begin{tabular}{|c|c|c|c|}
\hline Variables & OR & $95 \%$ CI & $\mathrm{p}$-value \\
\hline Age (years) & & & $<0.01$ \\
\hline $18-49$ & 1 & & \\
\hline$\geq 50$ & 2.46 & $1.80-3.38$ & \\
\hline Gender & & & 0.05 \\
\hline Female & 1 & & \\
\hline Male & 1.54 & $1.11-3.42$ & \\
\hline Diabetes duration (years) & & & $<0.01$ \\
\hline$<10$ & 1 & & \\
\hline$\geq 10$ & 2.04 & & \\
\hline Familial history of DKD & & & 0.02 \\
\hline No & 1 & & \\
\hline Yes & 1.83 & $1.15-4.28$ & \\
\hline Smoking & & & 0.18 \\
\hline No & 1 & & \\
\hline Yes & 1.30 & $0.43-5.01$ & \\
\hline Physical inactivity & & & 0.35 \\
\hline No & 1 & & \\
\hline Yes & 1.02 & $0.54-1.51$ & \\
\hline Hypertension & & & $<0.01$ \\
\hline No & 1 & & \\
\hline Yes & 1.96 & $1.21-6.99$ & \\
\hline Waist circumference $(\mathrm{cm})$ & & & 0.05 \\
\hline$<88$ & 1 & & \\
\hline$\geq 88$ & 1.54 & $1.09-4.39$ & \\
\hline Body Mass Index $\left(\mathrm{kg} / \mathrm{m}^{2}\right)$ & & & 0.27 \\
\hline$<25$ & 1 & & \\
\hline $25-29.9$ & 1.98 & $0.70-5.36$ & \\
\hline$\geq 30$ & 1.55 & $0.68-2.81$ & \\
\hline Total cholesterol (g/L) & & & 0.61 \\
\hline$<2$ & 1 & & \\
\hline$\geq 2$ & 1.72 & $0.92-4.25$ & \\
\hline Glycated haemoglobin (\%) & & & 0.36 \\
\hline$<7$ & 1 & & \\
\hline $7-8$ & 1.29 & $0.59-3.80$ & \\
\hline$>9$ & 1.07 & $0.60-2.53$ & \\
\hline
\end{tabular}

$\mathrm{DKD}=$ diabetic kidney disease; $\mathrm{OR}=$ odds ratio; $\mathrm{CI}$ = confidence interval. 
Table 3. Factors associated with diabetic kidney disease (multivariate regression).

\begin{tabular}{cccc}
\hline Variables & OR & 95\% CI & $P$ value \\
\hline Age & 1.5 & $1.1-3.4$ & 0.01 \\
Gender & 0.7 & $0.2-5.6$ & 0.57 \\
Familial history of DKD & 1.2 & $0.8-3.5$ & 0.09 \\
Duration of diabetes & 1.2 & $1.6-4.4$ & 0.03 \\
Hypertension & 2.5 & $1.4-4.6$ & 0.04 \\
Abdominal obesity & 1.0 & $0.4-2.9$ & 0.22 \\
Smoking & 0.9 & $0.5-3.8$ & 0.48 \\
Glycated haemoglobin & 0.56 & $0.4-4.7$ & 0.77 \\
\hline
\end{tabular}

$\mathrm{DKD}=$ diabetic kidney disease; $\mathrm{OR}=$ odds ratio; $\mathrm{CI}=$ confidence interval.

population and the other studies that are in majority hospital-based including patients with more advanced disease. One study in Benin including 300 type 2 diabetics found $7.7 \%$ of patients with eGFR $<60 \mathrm{ml} / \mathrm{min} / 1.73 \mathrm{~m}^{2}$ [9].

About $2.8 \%$ of diabetic patients included in this study presented with albuminuria between 30 and $300 \mathrm{mg} / 24 \mathrm{~h}$. Micro-albuminuria was reported in 27\% in Oman [10], 22\% in Bahrain [11], 21.2\% in Yemen [12], 16.1\% in Iraq [13]. In the African continent, prevalence of micro-albuminuria among type 2 diabetics is variable but higher with 23\% in Tunisia [14], 34.2\% in Egypt [15], 44\% in Sudan [16], and $45.8 \%$ in Tanzania [8].

In general, the reported higher incidence of renal complications in African diabetic patients compared to western countries is not clearly demonstrated as there is an important heterogeneity in published data depending on the study population, the methods used to define or assess diabetic kidney disease and the duration of observation period [7]. A systematic review describing CKD epidemiology in sub-Saharan Africa found a prevalence ranging from $4 \%$ to $24 \%$ among diabetic population [17].

\subsection{DKD Associated Factors}

Duration of diabetes, high blood pressure, advancing age, obesity and poor glycemic control were the identified risk factors of DKD in our patients.

The existence of a positive family history of DKD or high blood pressure had been identified in many studied as a major risk factor to develop renal among diabetic patients [18] [19] [20]. Genetic studies found many SNPs variants that might explain the familial clustering of DKD and difference between ethnic groups [21]. Patients presenting some variants of the ACE gene (double deletion allele DD) show a faster progression of diabetic nephropathy even though this polymorphism does not influence retinopathy [22].

Beyond genetic background that increases susceptibility to DKD several environmental factors may play a more important role in occurrence and progression of the disease. Low socioeconomic level, poor hyperglycemic control, 
hypertension, obesity, high protein diet, smoking and early life conditions were found to be associated with occurrence of DKD [23]. Hypertension had been extensively reported as a progression factor to ESRD but it can also be a confounding cause of kidney disease in diabetic patients [24] [25].

Early glycemic control is one of the main targets in primary prevention of diabetic nephropathy [4] [26] but other determinants of DKD are more controversial.

In an observational study of type 1 diabetic patients with a median follow-up of 9 years study, only smoking and baseline urinary albumin excretion rate were identified as predictors of progression from normo-albuminuria to micro-albuminuria or macro-albuminuria [27].

After high blood pressure, duration of diabetes was the second most powerful risk factor for DKD in our study. Compared with participants with duration of diabetes $<10$ years, those with duration of diabetes $\geq 10$ years had a $20 \%$ more chance of developing kidney disease. Duration of disease and bad of control of glycemia are well known risk factors of micro-albuminuria and overt nephropathy in diabetic patients [7] [11] [28]. However, in this study HbA1C level was not significantly associated presence of DKD probably because of the cross-sectional design that did not allow a good follow up of glycemia level.

Studies demonstrated that control of these risk factors with prescription of RAAS blockers can slow GFR decline and reduce all-cause mortality by half in diabetic patients [29]. However, early initiation of RAAS blockers in type 1 diabetes patients without micro-albuminuria did not show any substantial renal benefit [30]. In type 2 diabetes, several studies have the efficacy of RAAS inhibition to improve renal outcomes but data are strong enough to recommend RAAS inhibitors in absence of hypertension or albuminuria [31] [32].

New therapeutic molecules such as sodium-glucose co-transporter 2 (SGLT2) inhibitors, glucagon-like peptide-1 (GLP-1) agonists and aldosterone antagonists have demonstrated interesting results in reduction of renal and cardiovascular outcomes and will probably be widely used in management of DKD [33]. Finally, like in many chronic diseases, management of diabetic patients should not be restricted to one parameter or organ because there are various clinical, biological and socio-demographical determinants that may influence the outcomes. Building an integrated healthcare system with multidisciplinary management could help to achieve this goal [1] [3]. In such perspective, general practitioners or primary healthcare workers should have a central role for curative and preventive care activities.

\subsection{Limitations}

The cross-sectional design of our study represents a limitation. One reason of the lack of precision in diagnosis of kidney disease in diabetic patients is due to the observational and descriptive nature of the majority of community-based studies that does not allow a complete and adequate workup to identify the type of kidney injury. 
Kidney function was not measured 3 months later to ascertain chronicity of the disease and to roll out acute kidney injuries. Also, interpretation of associations found might be misleading as the study was descriptive.

\section{Conclusion}

Kidney disease is frequent among diabetic adult population living in Saint-Louis. The most common clinical presentation is hypertension with albuminuria. Patients' awareness is low and may contribute to late diagnosis and referral. To avoid complications that are particularly costly to manage, a lot of efforts should be made at primary care level to promote integrated programs for screening, early detection and management of diabetes and its complications including renal disease.

\section{Conflicts of Interest}

The authors declare no conflicts of interest regarding the publication of this paper.

\section{References}

[1] Pantalone, K.M., Hobbs, T.M., Wells, B.J., et al. (2015) Clinical Characteristics, Complications, Comorbidities and Treatment Patterns among Patients with Type 2 Diabetes Mellitus in a Large Integrated Health System. BMJ Open Diabetes Research \& Care, 3, e000093. https://doi.org/10.1136/bmjdrc-2015-000093

[2] Remmuzi, G., Schiepatti, A. and Ruggenenti, P. (2002) Nephropathy in Patients with Type-2 Diabetes. The New England Journal of Medicine, 346, 1145-1151. https://doi.org/10.1056/NEJMcp011773

[3] Ayodele, O.E., Alebiosu, C.O. and Salako, B.L. (2004) Diabetic Nephropathy a Review of the Natural History, Burden, Risk Factors and Treatment. Journal of the National Medical Association, 96, 1445-1454.

[4] Otani, T., Yokoyama, H., Hanai, K., Miura, J., Uchigata, Y. and Babazono, T. (2019) Rapid Increase in the Incidence of End-Stage Renal Disease in Patients with Type 1 Diabetes Having HbA1c 10\% or Higher for 15 Years. Clinical Pediatric Endocrinology, 28, 113-125. https://doi.org/10.1297/cpe.28.113

[5] Levey, A.S., Bosch, J.P., Lewis, J.B., Greene, T., Rogers, N. and Roth, D. (1999) A More Accurate Method to Estimate Glomerular Filtration Rate from Serum Creatinine: A New Prediction Equation. Annals of Internal Medicine, 130, 461-470. https://doi.org/10.7326/0003-4819-130-6-199903160-00002

[6] Retnakaran, R., Cull, C.A., Thorne, K.I., Adler, A.I., Holman, R.R. and UKPDS Study Group (2006) Risk Factors for Renal Dysfunction in Type 2 Diabetes: U.K. Prospective Diabetes Study 74. Diabetes, 55, 1832-1839. https://doi.org/10.2337/db05-1620

[7] Noubiap, J.J.N., Naidoo, J. and Kengne, A.P. (2015) Diabetic Nephropathy in Africa: A Systematic Review. World Journal of Diabetes, 6, 759-773. https://doi.org/10.4239/wjd.v6.i5.759

[8] Janmohamed, M.N., Kalluvya, S.E., Mueller, A., Kabangila, R., Smart, L.R., Downs, J.A., et al. (2013) Prevalence of Chronic Kidney Disease in Diabetic Adult Out-Patients in Tanzania. BMC Nephrology, 14, Article No. 183. 
https://doi.org/10.1186/1471-2369-14-183

[9] Vigan, J., Fagla, A.A.L., Bigot, C.E.P., Ahoui, S., Djrolo, F. and Bigot, A. (2017) Estimation of Glomerular Filtration Rate in African Black Diabetics Followed in Cotonou. RAFMI, 4, 10-14.

[10] Al-Futaisi, A., Al-Zakwani, I., Almahrezi, A., Al-Hajri, R., Al-Hashmi, L., et al. (2006) Prevalence and Predictors of Microalbuminuria in Patients with Type 2 Diabetes Mellitus: A Cross-Sectional Observational Study in Oman. Diabetes Research and Clinical Practice, 72, 212-215. https://doi.org/10.1016/j.diabres.2005.10.001

[11] Al-Salman, R.A., Al-Basri, H.A., Al-Sayyad, A.S. and Hearnshaw, H.M. (2009) Prevalence and Risk Factors of Albuminuria in Type 2 Diabetes in Bahrain. Journal of Endocrinological Investigation, 32, 746-751. https://doi.org/10.1007/BF03346530

[12] Bamashmoos, M.A. and Ganem, Y. (2013) Diabetic Nephropathy and Its Risk Factors in Type 2-Diabetic Patients in Sana'a City, Yemen. World Journal of Medical Sciences, 9, 147-152.

[13] Ali, A.A. and Al Lami, F.H. (2016) Prevalence and Determinants of Microalbuminurea among Type 2 Diabetes Mellitus Patients, Baghdad, Iraq 2013. Saudi Journal of Kidney Disease and Transplantation, 27, 348-355. https://doi.org/10.4103/1319-2442.178561

[14] Afifa, K., Asma, S.B., Nabil, H., Ahlem, B., Mounira, S., Kawthar, Y., et al. (2016) Screening for Nephropathy in Diabetes Mellitus: Is Micral-Test Valid among All Diabetics? International Journal of Chronic Diseases, 2016, Article ID: 2910627. https://doi.org/10.1155/2016/2910627

[15] Farahat, T.M., Elsaeed, G.K., Gazareen, S.S. and Elsayed, T.I. (2014) Prevalence of Proteinuria among Type 2 Diabetic Patients in Menoufia Governorate, Egypt. $\mathrm{Me}$ noufia Medical Journal, 27, 363. https://doi.org/10.4103/1110-2098.141710

[16] Rahamtalla, F.A., Elagib, A.A., Mahdi, A. and Ahmed, S.M. (2012) Prevalence of Microalbuminuria among Sudanese Type 2 Diabetic Patients at Elmusbah Center at Ombadda-Omdurman. IOSR Journal of Pharmacy, 2, 51-55. https://doi.org/10.9790/3013-25205155

[17] Stanifer, J.W., Jing, B., Tolan, S., Helmke, N., Mukerjee, R., et al. (2014) The Epidemiology of Chronic Kidney Disease in Sub-Saharan Africa: A Systematic Review and Meta-Analysis. The Lancet Global Health, 2, e174-e181. https://doi.org/10.1016/S2214-109X(14)70002-6

[18] Keller, C.K., Bergis, K.H., Fliser, D. and Ritz, E. (1996) Renal Findings in Patients with Short-Term Type 2 Diabetes. Journal of the American Society of Nephrology, 7, 2627-2635.

[19] Quinn, M., Angelico, M.C., Warram, J.H. and Krolewski, A.S. (1996) Familial Factors Determine the Development of Diabetic Nephropathy in Patients with IDDM. Diabetologia, 39, 940-945. https://doi.org/10.1007/BF00403913

[20] Aldukhayel, A. (2017) Prevalence of Diabetic Nephropathy among Type 2 Diabetic Patients in Some of the Arab Countries. International Journal of Health Sciences, 11, 60-63.

[21] Seaquist, E.R., Goetz, F.C., Rich, S. and Barbosa, J. (1989) Familial Clustering of Diabetic Kidney Disease. Evidence for Genetic Susceptibility to Diabetic Nephropathy. The New England Journal of Medicine, 320, 1161-1165. https://doi.org/10.1056/NEJM198905043201801

[22] Marre, M., Jeunemaitre, X., Gallois, Y., Rodier, M., Chatellier, G., et al. (1997) Contribution of Genetic Polymorphism in the Renin-Angiotensin System to the Development of Renal Complications in Insulin-Dependent Diabetes: Genetique de la 
Nephropathie Diabetique (GENEDIAB) Study Group. Journal of Clinical Investigation, 99, 1585-1595. https://doi.org/10.1172/JCI119321

[23] Rossing, P., Hougaard, P. and Parving, H.H. (2002) Risk Factors for Development of Incipient and Overt Diabetic Nephropathy in Type 1 Diabetic Patients: A 10-Year Prospective Observational Study. Diabetes Care, 25, 859-864.

https://doi.org/10.2337/diacare.25.5.859

[24] Brancati, F.L., Whittle, J.C., Whelton, P.K., Seidler, A.J. and Klag, M.J. (1992) The Excess Incidence of Diabetic End-Stage Renal Disease among Blacks. A Population-Based Study of Potential Explanatory Factors. JAMA, 268, 3079-3084. https://doi.org/10.1001/jama.1992.03490210061036

[25] Retnakaran, R., Cull, C.A., Thorne, K.I., Adler, A.I., Holman, R.R. and UKPDS Study Group (2006) Risk Factors for Renal Dysfunction in Type 2 Diabetes: U.K. Prospective Diabetes Study 74. Diabetes, 55, 1832-1839. https://doi.org/10.2337/db05-1620

[26] Group, A.S., Cushman, W.C., Evans, G.W., Byington, R.P., Goff, D.C., et al. (2010) Effects of Intensive Blood-Pressure Control in Type 2 Diabetes Mellitus. The New England Journal of Medicine, 362, 1575-1585.

https://doi.org/10.1056/NEJMoa1001286

[27] Hovind, P., Tarnow, L., Rossing, P., Jensen, B.R., Graae, M., Torp, I., et al. (2004) Predictors for the Development of Microalbuminuria and Macroalbuminuria in $\mathrm{Pa}$ tients with Type 1 Diabetes: Inception Cohort Study. BMJ, 328, 1105. https://doi.org/10.1136/bmj.38070.450891.FE

[28] Zoungas, S., Woodward, M., Li, Q., Cooper, M.E., Hamet, P., et al. (2014) Impact of Age, Age at Diagnosis and Duration of Diabetes on the Risk of Macrovascular and Microvascular Complications and Death in Type 2 Diabetes. Diabetologia, 57, 2465-2474. https://doi.org/10.1007/s00125-014-3369-7

[29] Andrésdóttir, G., Jensen, M.L., Carstensen, B., Parving, H.H., Kasper Rossing, K., et al. (2014) Improved Survival and Renal Prognosis of Patients with Type 2 Diabetes and Nephropathy with Improved Control of Risk Factors. Diabetes Care, 37, 1660-1667. https://doi.org/10.2337/dc13-2360

[30] Mauer, M., Zinman, B., Gardiner, R., Suissa, S., Sinaiko, A., et al. (2009) Renal and Retinal Effects of Enalapril and Losartan in Type 1 Diabetes. The New England Journal of Medicine, 361, 40-51. https://doi.org/10.1056/NEJMoa0808400

[31] Ruggenenti, P., Fassi, A., Ilieva, A.P., et al. (2004) Preventing Microalbuminuria in Type 2 Diabetes. The New England Journal of Medicine, 351, 1941-1951. https://doi.org/10.1056/NEJMoa042167

[32] Zoungas, S., Chalmers, J., Neal, B., et al. (2014) Follow-Up of Blood-Pressure Lowering and Glucose Control in Type 2 Diabetes. The New England Journal of Medicine, 371, 1392-1406. https://doi.org/10.1056/NEJMoa1407963

[33] Lytvyn, Y., Bjornstad, P., Pun, N., et al. (2016) New and Old Agents in the Management of Diabetic Nephropathy. Current Opinion in Nephrology and Hypertension, 25, 232-239. https://doi.org/10.1097/MNH.0000000000000214 


\section{Annex: Data Collection Questionnaire}

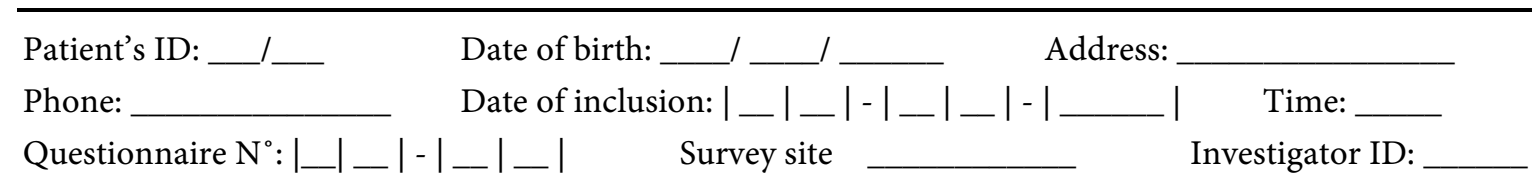

SOCIO-DEMOGRAPHICAL DATA

Marital status: ; Disease awareness (before current survey):

Occupation: ; Diabetes duration (since diagnosis): years

\section{MEDICAL PAST}

MEDICAL:

$\square$ Hypertension $\quad \square$ Diabetes $\quad \square$ Overt nephropathy $\quad \square$ Proteinuria $\quad \square$ Repeated UTI
$\square$ Other diabetic cases in the family (_
$\square$ Physical activity $\quad \square$ Smoking

\section{SURGICAL:}

Chirurgie autres que césarienne (Préciser

GYNECO-OBSTETRICAL (if female):

Number of pregnancies
$\square$ Fotal macrosomia
$\square \mathrm{C}$ section delivery (indication?

\section{ONGOING TREATMENTS:}

$\square$ Dietary measures (_ $) \quad \square$ Oral antidiabetics (_
$\square$ Insuline (_
Other medications (_ Phytotherapy (__

\section{CLINICAL EXAMINATION}

General appearance ; Edema ; Skin dehydration :

Vital signs: $\mathrm{T}$ C; BP $\mathrm{mm} \cdot \mathrm{Hg}$; Pulse bpm; RF cycles/min; Weight kg; Height $\mathrm{cm}$;

Waist circumference cm; Hip circumference $\mathrm{cm}$

Urinary strips: Proteins Glucose Blood __ Leucocytes Nitrites Gravity

\section{BIOLOGICAL TESTS}

Fasting blood glucose: g/l; HbA1C: $\%$

$\mathrm{Hb}$ g/dl; Serum creatinine $\mathrm{mg} / \mathrm{l} ; \mathrm{UAE}$ $\mathrm{g} / 24 \mathrm{~h}$ 